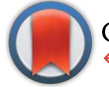

CrossMark \&click for updates

Cite this: Chem. Sci., 2015, 6, 4242

Received 23rd March 2015 Accepted 25th April 2015

DOI: $10.1039 / \mathrm{c5sc01052g}$

www.rsc.org/chemicalscience

\section{Diastereodivergent organocatalysis for the asymmetric synthesis of chiral annulated furans $\uparrow$}

\begin{abstract}
Charlie Verrier ${ }^{b}$ and Paolo Melchiorre*ab
Disclosed herein is a stereoselective method for the synthesis of 2,3-furan fused carbocycles bearing adjacent quaternary and tertiary carbon stereocenters. The chemistry is based on an asymmetric addition of $\beta$-ketoesters to 2-(1-alkynyl)-2-alkene-1-ones catalysed by natural cinchona alkaloids followed by a silver-catalysed intramolecular cycloisomerisation. By exploiting the distinct catalysis modes of quinine, which can act either as a general base or, upon opportune modifications, as a phase transfer catalyst, a complete switch of the enforced sense of diastereoinduction is achieved. The stereodivergent systems enable access to the full matrix of all possible stereoisomeric products.
\end{abstract}

\section{Introduction}

This research project was motivated by our interest in devising a direct and versatile strategy for stereoselectively assembling chiral annulated furans. ${ }^{1}$ As shown in Fig. 1, many biologically active compounds and natural products possess a furan system fused to rings of various sizes and adorned with multiple stereocenters. ${ }^{2}$ Despite significant advances in preparing racemic 2,3 -furan-fused carbocycles, ${ }^{3}$ there are only a few catalytic strategies for their direct stereoselective synthesis. ${ }^{4}$

Herein, we describe a straightforward synthetic strategy for accessing six- and seven-membered-ring furan derivatives bearing adjacent quaternary and tertiary carbon stereocentres in very high yields and stereoselectivities. The chemistry, which uses readily available substrates and catalysts, is based on a twostep sequential process whereby an organocatalytic asymmetric addition of $\beta$-ketoesters 2 to cyclic 2-(1-alkynyl)-2-alkene-1-ones

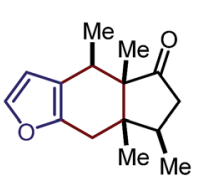

pinguisone

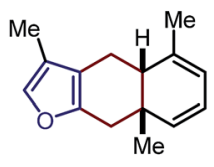

tubipofuran

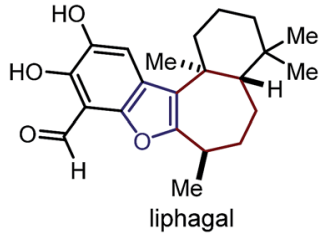

liphagal
Fig. 1 Naturally occurring chiral annulated furans.

${ }^{a}$ ICREA - Catalan Institution for Research and Advanced Studies, Pg. Lluís Companys 23, 08010 Barcelona, Spain. E-mail: pmelchiorre@iciq.es; Tel: +34 977920208 ${ }^{b} I C I Q$ - Institute of Chemical Research of Catalonia, Av. Països Catalans 16, 43007 Tarragona, Spain

$\dagger$ Electronic supplementary information (ESI) available: Complete experimental procedures and full compound characterisation, including HPLC traces and NMR spectra (PDF). CCDC 1046068 and 1046069. For ESI and crystallographic data in CIF or other electronic format see DOI: $10.1039 / \mathrm{c} 5 \mathrm{sc} 01052 \mathrm{~g}$
1 (ref. 5 and 6) is followed by a silver-catalysed intramolecular cycloisomerisation of the transient allenyl ketone $\mathrm{p}^{7}$ intermediate 3 (Scheme 1). Significantly, we have identified two distinct catalytic systems which infer complementary diastereoselectivities, thereby enabling access to the full complement of stereoisomers of the annulated products $\mathbf{4}$ and $\mathbf{5}$ at will. ${ }^{\mathbf{8}}$

\section{Results and discussion}

Our initial explorations focused on the reaction between 2phenylethynyl-2-cyclohexen-1-one 1a (ref. 9) and the cyclic

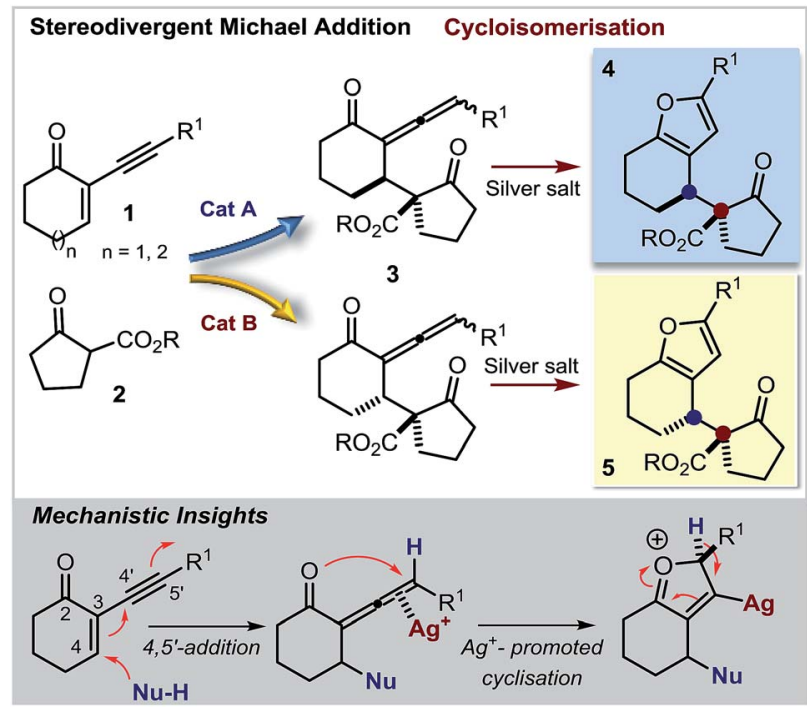

Scheme 1 Diastereodivergent and enantioselective synthesis of chiral 2,3-furan fused carbocycles via an organocatalytic 4,5'-addition/ cycloisomerisation sequence promoted by distinct organocatalysts (Cat A \& Cat B) and a silver catalyst, respectively. 
ketoester 2a in DCM and in the presence of $5 \mathrm{~mol} \%$ of a chiral tertiary amine, which could act as a general base catalyst (deprotonative activation of $\mathbf{2 a}$ ). The process was conducted in two sequential steps, with the initial organocatalytic path exclusively providing the corresponding allenyl ketone of type 3 (ref. 10) (Scheme 1) by means of a selective 4,5'-addition. ${ }^{6}$ Upon filtering out the chiral amine through $\mathrm{SiO}_{2}$ and evaporation of the solvent, the cycloisomerisation of crude $3 \mathbf{a}$ was achieved by applying a slightly modified Marshall procedure ${ }^{7,11}$ (using 10 $\mathrm{mol} \% \mathrm{AgNO}_{3}$, and AcOEt at $40{ }^{\circ} \mathrm{C}$ ) to afford the diastereomeric adducts $\mathbf{4}$ and $\mathbf{5}$.

We focused on identifying chiral organocatalysts that could infer high stereocontrol in the initial $4,5^{\prime}$-addition reaction. Representative results of our extensive studies are listed in Table 1, with more details reported in the ESI. $\dagger$ Intriguingly, natural cinchona alkaloid derivatives, ${ }^{12}$ acting as general base catalysts, ${ }^{13}$ afforded impressive levels of stereoselectivity (4a formed with a dr of up to $19: 1$, and an ee of up to $99 \%$,

Table 1 Selected optimisation studies on the model reaction ${ }^{a}$

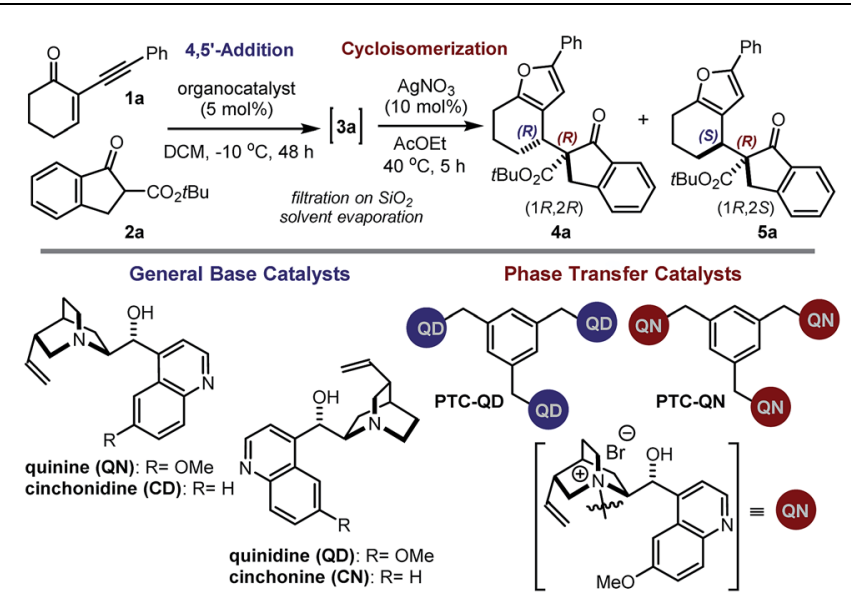

\begin{tabular}{lllll} 
Entry & Catalyst & Yield $^{b}(\%)$ & $\mathbf{4 a}: \mathbf{5} \mathbf{a ~ r a t i o}^{c}$ & ee $(\%)$ major isomer \\
\hline 1 & QN & 66 & $19: 1$ & $99(1 R, 2 R)$ \\
2 & CD & 62 & $12: 1$ & $99(1 R, 2 R)$ \\
3 & QD & 82 & $18: 1$ & $98(1 S, 2 S)$ \\
4 & CN & 84 & $17: 1$ & $98(1 S, 2 S)$ \\
$5^{e}$ & QN & 83 & $19: 1$ & $99(1 R, 2 R)$ \\
6 & OMe-QN & 15 & $1: 1.5$ & $<5$ \\
7 & QN-OH & $<5$ & - & - \\
$8^{f, g}$ & PTC-QN & 73 & $1: 13$ & $86(1 R, 2 S)$ \\
$9^{f}$ & PTC-QD & 89 & $1: 19$ & $87(1 S, 2 R)$
\end{tabular}

${ }^{a}$ Reactions were performed in DCM at $-10{ }^{\circ} \mathrm{C}$ on a $0.2 \mathrm{mmol}$ scale using 1.2 equiv. of $2 \mathrm{a}$, with $[\mathbf{1 a}]_{0}=0.1 \mathrm{M}$. After 48 hours, the $4,5^{\prime}$ addition was quenched by filtration through a pad of silica. Upon evaporation of the solvent, the cycloisomerisation of the intermediate 3a was conducted by dissolving the crude residue in $2 \mathrm{~mL}$ of AcOEt and adding $10 \mathrm{~mol} \%$ of $\mathrm{AgNO}_{3} .{ }^{b}$ Yield of the isolated products $4 \mathrm{a}$ and 5a (diastereomeric mixture). ${ }^{c}$ Diastereomeric ratio determined by ${ }^{1} \mathrm{H}$ NMR analysis of the crude mixture upon cycloisomerisation. ${ }^{d}$ Enantiomeric excess, as determined by HPLC analysis on chiral stationary phases, refers to the major diastereoisomer; the absolute configuration is specified between brackets. ${ }^{e}[\mathbf{1 a}]_{0}=0.5 \mathrm{M}$. ${ }^{f}$ Performed at $-20{ }^{\circ} \mathrm{C}$ in a $5: 1$ mixture of $\mathrm{DCM} / 33 \% \mathrm{~K}_{2} \mathrm{CO}_{3}$ aq., with $[\mathbf{1 a}]_{0}=0.2 \mathrm{M}^{g}{ }^{g}$ Performed using $10 \mathrm{~mol} \%$ of catalyst. entries 1-4), largely outperforming any other synthetic catalyst tested (see ESI $\dagger$ ).

Importantly, the use of the "pseudoenantiomeric" catalysts quinine (QN) and quinidine (QD) secured access to both antipodes of the adduct 4 with excellent selectivity (entries $5 \& 3$, respectively). Protection of the quinine hydroxy moiety resulted in a greatly reduced reactivity along with a complete loss of stereocontrol (entry 6). Mechanistically, this suggests that the cinchona catalysts might operate through a bifunctional activation mode, simultaneously binding and activating the two reacting partners. ${ }^{\mathbf{1 3 a , 1 4}}$ Interestingly, the cupreidine derivative QN-OH, a catalyst with a proven ability to promote the highly stereoselective addition of $\beta$-ketoesters to cyclic enones, remained completely inactive in our system (entry 7$).{ }^{15}$

We then modified the cinchona alkaloid scaffold by alkylating the basic bridgehead nitrogen of the quinuclidine core, the classical approach for achieving catalysts suitable for use as phase transfer catalysts (PTCs) ${ }^{16}$ Among the many PTCs tested in the model reaction (see ESI $\uparrow$ for details), the cinchonaderived trimeric species PTC-QN and PTC-QD, ${ }^{17}$ easily obtained by the poly-alkylation of quinine and quinidine with 1,3,5tris(bromomethyl)benzene, provided the most interesting results. When performing the reaction in DCM and in the presence of $33 \% \mathrm{~K}_{2} \mathrm{CO}_{3}$ aq., a complete switch of the enforced sense of diastereoinduction was achieved, so that the adduct $\mathbf{5}$ was almost exclusively formed in high optical purity (entries 8 \& 9).

These findings allowed us to fully control the stereochemical outcome of the process, enabling the generation of any stereoisomer of the annulated furans $\mathbf{4}$ and $\mathbf{5}$ at will. This is considered a challenging goal because when asymmetric catalysis is applied to processes that generate two stereogenic centres in one product, there is generally no obvious means of modifying a catalyst to modulate the relative sense of those two centres. ${ }^{8}$ In this case, the two diastereodivergent systems are based on different organocatalysts, but are derived from the common chiral core of natural cinchona alkaloids. The divergent stereocontrol arises from the ability of the cinchona catalysts to execute distinct modes of catalysis for activating the reagents (base catalysis vs. phase transfer catalysis, Scheme 2).

Having identified two distinct catalytic systems that can selectively channel the reaction manifolds toward complementary diastereochemical outcomes, we examined the scope of the two-step process using QN (5 mol\%) as a general base catalyst. As revealed in Table 2, the method shows a wide substrate generality and an excellent level of stereoselectivity, providing access to a variety of complex annulated furans 4 adorned with two vicinal quaternary and tertiary stereocentres. We first tested the possibility of modifying the cyclic scaffold of the 2-(1-alkynyl)-2-alken-1-one component 1 . The cycloheptenone derivative reacted smoothly to provide the sevenmembered-ring furan $\mathbf{4 b}$ in high optical purity (entry 2). In contrast, the cyclopentenone derivative was not a suitable substrate, since a complete lack of reactivity in the silver-catalysed intramolecular cycloisomerisation step was observed. Different substitution patterns on the aromatic moiety of 1 were well-tolerated, regardless of their electronic properties (entries 


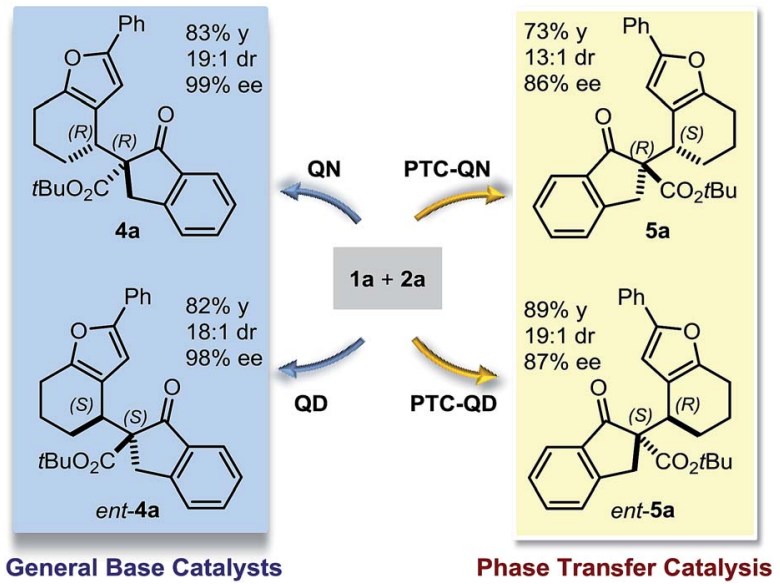

Scheme 2 Accessing the full matrix of the stereoisomers of the annulated furans $4 a$ and $5 a$. When QN and QD function as general base catalysts, both enantiomers of the diastereoisomer 4 a could be accessed. Modifying the catalyst structure to induce a different activation pattern, namely phase transfer catalysis, enables direct access to both antipodes of $5 \mathrm{a}$ using PTC-QN and PTC-QD

Table 2 Synthesis of chiral annulated furans by general base catalysis: nucleophile and electrophile scope ${ }^{a}$

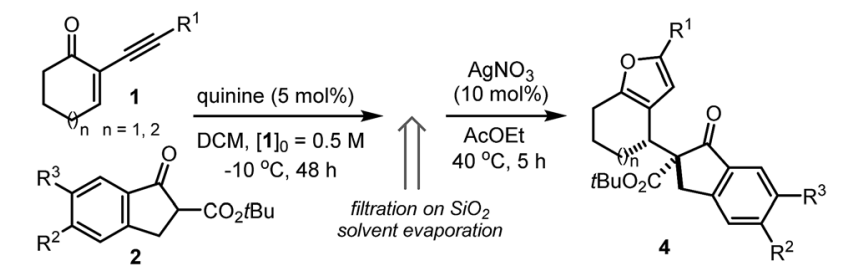

\begin{tabular}{llllllll}
\hline Entry & $R^{1}, n$ & $R^{2}$ & $R^{3}$ & $\mathbf{4}$ & $\operatorname{Yield}^{b}(\%)$ & $\mathrm{dr}^{c}$ & $\mathrm{ee}^{d}(\%)$ \\
\hline 1 & $\mathrm{Ph}, 1$ & $\mathrm{H}$ & $\mathrm{H}$ & $\mathbf{a}$ & 83 & $19: 1$ & 99 \\
2 & $\mathrm{Ph}, 2$ & $\mathrm{H}$ & $\mathrm{H}$ & $\mathbf{b}$ & 75 & $12: 1$ & 97 \\
3 & $4-\mathrm{MeOC}_{6} \mathrm{H}_{4}, 1$ & $\mathrm{H}$ & $\mathrm{H}$ & $\mathbf{c}$ & 83 & $19: 1$ & 99 \\
4 & $4-\mathrm{CF}_{3} \mathrm{C}_{6} \mathrm{H}_{4}, 1$ & $\mathrm{H}$ & $\mathrm{H}$ & $\mathbf{d}$ & 90 & $19: 1$ & 99 \\
5 & $4-\mathrm{MeC}_{6} \mathrm{H}_{4}, 1$ & $\mathrm{H}$ & $\mathrm{H}$ & $\mathbf{e}$ & 83 & $19: 1$ & 99 \\
& & & & & & & \\
6 & & & & & & & \\
\end{tabular}

${ }^{a}$ Reactions were performed at $-10^{\circ} \mathrm{C}$ on a $0.2 \mathrm{mmol}$ scale and using 1.2 equiv. of 2. After 48 hours, the organocatalytic $4,5^{\prime}$-addition was quenched by filtration through a pad of silica. Upon evaporation of the solvent, the crude residue was dissolved in $2 \mathrm{~mL}$ of AcOEt and 10 mol\% of $\mathrm{AgNO}_{3}$ was added. ${ }^{b}$ Yield of the isolated products 4 (diastereomeric mixture). ${ }^{c}$ Diastereomeric ratio determined by ${ }^{1} \mathrm{H}$ NMR analysis of the crude mixture upon cycloisomerization. ${ }^{d}$ Enantiomeric excess determined by HPLC analysis on chiral stationary phases. ${ }^{e}$ The absolute configuration of $\mathbf{4 h}$ was unambiguously inferred by X-ray analysis, see ref. 18 .
3-5). In addition, an alkyne bearing a vinylic substituent (entry 6) provided the corresponding furan $\mathbf{4 f}$ with high stereocontrol, albeit with a moderate chemical yield. A limitation of the system is that we have thus far failed to react alkynes bearing alkyl or TMS groups, and linear substrates.

As for the nucleophilic partners 2, electronic variations in the indanone ring were possible, as both electron donating and withdrawing substituents gave the desired products in high yields and excellent diastereo- and enantioselectivities (entries 7-11). Efforts to react six-membered cyclic and linear $\beta$-ketoesters need further optimization, since only traces of the corresponding products could be obtained.

We then evaluated the synthetic potential of the PTC-mediated system. As depicted in Table 3, the reactions catalysed by 5 mol\% of PTC-QD showed a comparable versatility to the system under general base catalysis, but secured a complementary diastereoselectivity, since the opposite diastereoisomers 5 of

Table 3 Synthesis of chiral annulated furans under PTC conditions: nucleophile and electrophile scope ${ }^{a}$

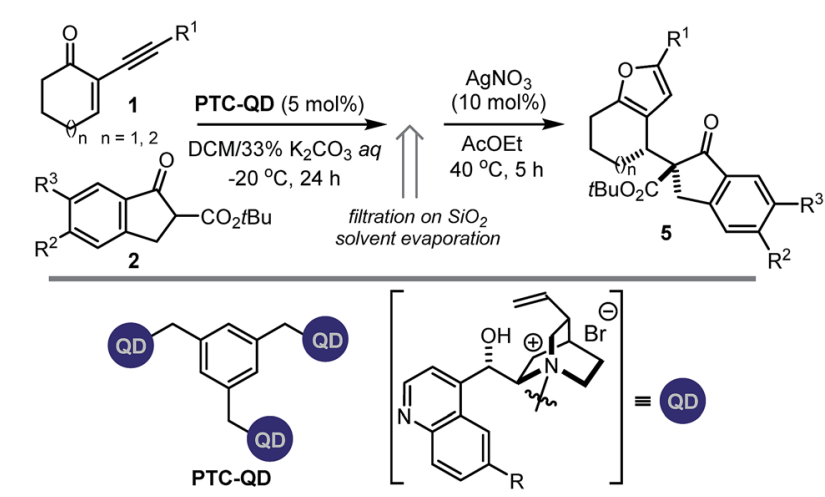

\begin{tabular}{|c|c|c|c|c|c|c|c|}
\hline Entry & $R^{1}, n$ & $R^{2}$ & $R^{3}$ & 5 & Yield $^{b}(\%)$ & $\mathrm{dr}^{c}$ & $\mathrm{ee}^{d}(\%)$ \\
\hline $1^{e}$ & Ph, 1 & $\mathrm{H}$ & $\mathrm{H}$ & $\mathbf{a}$ & 89 & $19: 1$ & 87 \\
\hline 2 & $\mathrm{Ph}, 2$ & $\mathrm{H}$ & $\mathrm{H}$ & $\mathbf{b}$ & 81 & $9.5: 1$ & 93 \\
\hline 3 & $4-\mathrm{MeOC}_{6} \mathrm{H}_{4}, 1$ & $\mathrm{H}$ & $\mathrm{H}$ & c & 87 & $19: 1$ & 89 \\
\hline 4 & $4-\mathrm{CF}_{3} \mathrm{C}_{6} \mathrm{H}_{4}, 1$ & $\mathrm{H}$ & $\mathrm{H}$ & d & 84 & $8: 1$ & 81 \\
\hline 5 & $4-\mathrm{MeC}_{6} \mathrm{H}_{4}, 1$ & $\mathrm{H}$ & $\mathrm{H}$ & $\mathbf{e}$ & 82 & $19: 1$ & 91 \\
\hline $6^{f}$ &, 1 & $\mathrm{H}$ & $\mathrm{H}$ & f & 53 & $19: 1$ & 92 \\
\hline $7^{f}$ & Ph, 1 & $\mathrm{MeO}$ & $\mathrm{MeO}$ & i & 62 & $16: 1$ & 72 \\
\hline $8^{f}$ & Ph, 1 & $\mathrm{H}$ & $\mathrm{Br}$ & $\mathbf{h}$ & 78 & $11: 1$ & 77 \\
\hline 9 & Ph, 1 & $\mathrm{H}$ & $\mathrm{Me}$ & $\mathbf{j}$ & 87 & $19: 1$ & 87 \\
\hline 10 & Ph, 1 & $\mathrm{~F}$ & $\mathrm{H}$ & $\mathbf{k}$ & 87 & $15: 1$ & 85 \\
\hline 11 & Ph, 1 & $\mathrm{Br}$ & $\mathrm{H}$ & 1 & 70 & $19: 1$ & 83 \\
\hline
\end{tabular}

${ }^{a}$ Reactions were performed at $-20{ }^{\circ} \mathrm{C}$ in a $5: 1$ mixture of DCM/33\% $\mathrm{K}_{2} \mathrm{CO}_{3}$ aq., on a $0.2 \mathrm{mmol}$ scale and using 1.2 equiv. of 2 ; with $[\mathbf{1 a}]_{0}=$ $0.2 \mathrm{M}$. After 24 hours, the $4,5^{\prime}$-addition was quenched by filtration through a pad of silica. Upon evaporation of the solvent, the crude residue was dissolved in $2 \mathrm{~mL}$ of AcOEt and $10 \mathrm{~mol} \%$ of $\mathrm{AgNO}_{3}$ was added. ${ }^{b}$ Yield of the isolated products 5 (diastereomeric mixture). ${ }^{c}$ Diastereomeric ratio determined by ${ }^{1} \mathrm{H}$ NMR analysis of the crude mixture upon cycloisomerisation. ${ }^{d}$ Enantiomeric excess determined by HPLC analysis on chiral stationary phases. ${ }^{e}$ The absolute configuration of 5a was unambiguously inferred by X-ray analysis, see ref. $18{ }^{f}$ Reactions were performed at $-10^{\circ} \mathrm{C}$ using $1.5 \mathrm{~mol} \%$ of catalyst. 
the annulated furans were almost exclusively formed with high enantiocontrol.

The relative and absolute configuration of products $\mathbf{4 h}$ and 5 a were unambiguously inferred by anomalous dispersion X-ray crystallographic analysis. ${ }^{18}$

\section{Conclusions}

In conclusion, we have developed an operationally simple, twostep process to access a variety of stereochemically dense 2,3furan fused carbocycles bearing adjacent quaternary ${ }^{\mathbf{1 9}}$ and tertiary stereocentres. The salient feature of our study is that complementary organocatalytic systems, both using natural cinchona-derived catalysts, have been identified, which ensure highly selective access to the full matrix of all possible stereoisomeric products at will.

\section{Acknowledgements}

This work was supported by the ICIQ Foundation, and MINECO (CTQ2013-45938-P). C.V. thanks CMIRA 2013-EXPLO'RA PRO, grant number: 006402-01 (region Rhone-Alpes, France) for postdoctoral support. We also thank MINECO for support through the Severo Ochoa Excellence Accreditation 2014-2018 (SEV-2013-0319) and the CELLEX Foundation through the CELLEX-ICIQ high throughput experimentation platform.

\section{Notes and references}

1 For recent reviews on furan synthesis, see: $(a)$ W. J. Moran and A. Rodríguez, Org. Prep. Proced. Int., 2012, 44, 103; (b) A. V. Gulevich, A. S. Dudnik, N. Chernyak and V. Gevorgyan, Chem. Rev., 2013, 113, 3084; (c) H. N. C. Wong, K.-S. Yeung and Z. Yang, in Comprehensive Heterocyclic Chemistry III, ed. A. R. Katrizky, C. A. Ramsden, E. F. V. Scriven and R. J. K. Taylor, Elsevier, Oxford, 2008, ch. 3.06, p. 407.

2 (a) B. A. Keay, J. M. Hopkins and P. W. Dibblein, in Comprehensive Heterocyclic Chemistry III, ed. A. R. Katrizky, C. A. Ramsden, E. F. V. Scriven and R. J. K. Taylor, Elsevier, Oxford, 2008, ch. 3.08, p. 571; (b) H. H. Issa, J. Tanaka and T. Higa, J. Nat. Prod., 2003, 66, 251. Pinguisone: (c) S. Bernasconi, P. Gariboldi, G. Jommi, S. Montanari and M. Sisti, J. Chem. Soc., Perkin Trans. 1, 1981, 2394. Tubipofuran: (d) K. Iguchi, K. Mori, M. Suzuki, H. Takahashi and Y. Yamada, Chem. Lett., 1986, 1789; (e) E. P. Kündig, R. Cannas, M. Laxmisha, L. Ronggang and S. Tchertchian, J. Am. Chem. Soc., 2003, 125, 5642. Liphagal: $(f)$ F. Marion, D. E. Williams, B. O. Patrick, I. Hollander, R. Mallon, S. C. Kim, D. M. Roll, L. Feldberg, R. van Soest and R. J. Andersen, Org. Lett., 2006, 8, 321; $(g)$ J. J. Day, R. M. McFadden, S. C. Virgil, H. Kolding, J. L. Alleva and B. M. Stoltz, Angew. Chem., Int. Ed., 2011, 50, 6814 .

3 For selected examples, see: (a) A. S. K. Hashmi, P. Haufe, C. Schmid, A. Rivas Nass and W. Frey, Chem.-Eur. J., 2006, 12, 5376; (b) Z. Dong, C.-H. Liu, Y. Wang, M. Lin and
Z.-X. Yu, Angew. Chem., Int. Ed., 2013, 52, 14157; (c) L. Zhou, M. Zhang, W. Li and J. Zhang, Angew. Chem., Int. Ed., 2014, 53, 6542.

4 (a) F. Liu, D. Qian, L. Li, X. Zhao and J. Zhang, Angew. Chem., Int. Ed., 2010, 49, 6669; (b) V. Rauniyar, Z. J. Wang, H. E. Burks and F. D. Toste, J. Am. Chem. Soc., 2011, 133, 8486; (c) Z.-M. Zhang, P. Chen, W. Li, Y. Niu, X.-L. Zhao and J. Zhang, Angew. Chem., Int. Ed., 2014, 53, 4350.

5 It is of note that, to date, only a single example of enantioselective catalytic Michael addition to activated enynes to afford enantio-enriched 2,3-allenoates has been reported, see: H. Qian, X. Yu, J. Zhang and J. Sun, J. Am. Chem. Soc., 2013, 135, 18020.

6 For examples of non-stereoselective $4,5^{\prime}$-additions of nucleophiles to 1 leading to racemic 1,2-allenyl ketones of type 3, see: (a) X. Yu, H. Ren, Y. Xiao and J. Zhang, Chem.Eur. J., 2008, 14, 8481; (b) X. Yu and J. Zhang, Adv. Synth. Catal., 2011, 353, 1265.

7 (a) J. A. Marshall and X. J. Wang, J. Org. Chem., 1991, 56, 960; (b) J. A. Marshall and G. S. Bartley, J. Org. Chem., 1994, 59, 7169. For a review, see; (c) P. Belmont and E. Parker, Eur. J. Org. Chem., 2009, 6075.

8 For highlight articles on diastereo-divergent strategies that give access to the full matrix of product stereoisomers from the same set of starting materials, see: (a) C. S. Schindler and E. N. Jacobsen, Science, 2013, 340, 1052; (b) M. T. Oliveira, M. Luparia, D. Audisio and N. Maulide, Angew. Chem., Int. Ed., 2013, 52, 13149. For selected examples, see: (c) S. Krautwald, D. Sarlah, M. A. Schafroth and E. M. Carreira, Science, 2013, 340, 1065; (d) S. Krautwald, M. A. Schafroth, D. Sarlah and E. M. Carreira, J. Am. Chem. Soc., 2014, 136, 3020; (e) X. Tian, C. Cassani, Y. Liu, A. Moran, A. Urakawa, P. Galzerano, E. Arceo and P. Melchiorre, J. Am. Chem. Soc., 2011, 133, 17934; (f) M. Luparia, M. T. Oliveira, D. Audisio, R. Goddard and N. Maulide, Angew. Chem., Int. Ed., 2011, 50, 12631; $(g)$ A. Nojiri, N. Kumagai and M. Shibasaki, J. Am. Chem. Soc., 2009, 131, 3779; (h) B. Simmons, A. M. Walji and D. W. C. MacMillan, Angew. Chem., Int. Ed., 2009, 48, 4349; (i) Y. Chi, S. T. Scroggins and J. M. Fréchet, J. Am. Chem. Soc., 2008, 130, 6322; (j) B. Wang, F. Wu, Y. Wang, X. Liu and L. Deng, J. Am. Chem. Soc., 2007, 129, 768.

9 Metal-catalysed cycloisomerisation of 2-(1-alkynyl)-2-alkene1-ones 1 has been widely used in the non-stereoselective preparation of furans, see: (a) T. Yao, X. Zhang and R. C. Larock, J. Am. Chem. Soc., 2004, 126, 11164; (b) T. Yao, X. Zhang and R. C. Larock, J. Org. Chem., 2005, 70, 7679; (c) N. T. Patil, H. Wu and Y. Yamamoto, J. Org. Chem., 2005, 70, 4531. For stereoselective variants, see ref. $4 \mathrm{a}$ and $\mathrm{b}$.

10 Under the reaction conditions detailed in Table 1, the allenyl ketone intermediate $\mathbf{3 a}$ is produced with very poor diastereomeric purity (dr ranging from $1: 1$ to $1.5: 1$ ) as a consequence of the lack of stereocontrol over the axial chirality. This stereochemical information, however, is 
eventually lost during the cycloisomerisation to give the annulated furans.

11 All attempts to perform the organocatalytic 4,5'-addition/ cycloisomerisation sequence in one-pot have met with failure. For recently reported examples showing the compatibility of silver with organocatalysis, see: (a) D. Hack, P. Chauhan, K. Deckers, G. N. Hermann, L. Mertens, G. Raabe and D. Enders, Org. Lett., 2014, 16, 5188 and references therein; (b) I. Ortín and D. J. Dixon, Angew. Chem., Int. Ed., 2014, 53, 3462.

12 C. E. Song, Cinchona Alkaloids in Synthesis and Catalysis; Wiley-VCH: Weinheim, Germany, 2009.

13 For a pioneering work, see: $(a)$ H. Hiemstra and H. Wynberg, J. Am. Chem. Soc., 1981, 103, 417. For a review: (b) $\mathrm{S}$. Ingemann and $\mathrm{H}$. Hiemstra, in Comprehensive Enantioselective Organocatalysis, ed. P. Dalko, Wiley-VCH, Weinheim, Germany, 2013, vol. 1, ch. 6, p. 119, For selected examples of highly enantioselective reactions catalyzed by natural cinchona alkaloids, see: (c) S. Lou, B. M. Taoka, A. Ting and S. E. Schaus, J. Am. Chem. Soc., 2005, 127, 11256; (d) G. Bartoli, M. Bosco, A. Carlone,
A. Cavalli, M. Locatelli, A. Mazzanti, P. Ricci, L. Sambri and P. Melchiorre, Angew. Chem., Int. Ed., 2006, 45, 4966.

14 For a computational study, see: C. S. Cucinotta, M. Kosa, P. Melchiorre, A. Cavalli and F. L. Gervasio, Chem.-Eur. J., 2009, 15, 7913.

15 F. Wu, H. Li, R. Hong and L. Deng, Angew. Chem., Int. Ed., 2006, 45, 947.

16 Asymmetric Phase Transfer Catalysis, ed. K. Maruoka, WileyVCH, Weinheim, Germany, 2008.

17 (a) W. E. Siew, C. Ates, A. Merschaert and A. G. Livingston, Green Chem., 2013, 15, 663; (b) R. Sallio, S. Lebrun, N. Schifano-Faux, J.-F. Goossens, F. Agbossou-Niedercorn, E. Deniau and C. Michon, Synlett, 2013, 24, 1785.

$18 \mathrm{ESI} \dagger$ The absolute configuration of the light-atom molecule 5a was assigned using the X-ray diffraction methodology described in: E. C. Escudero-Adán, J. Benet-Buchholz and P. Ballester, Acta Crystallogr., Sect. B: Struct. Sci., Cryst. Eng. Mater., 2014, 70, 660.

19 For a review highlighting modern catalytic enantioselective methods to forge quaternary carbon stereocentres, see: K. W. Quasdorf and L. E. Overman, Nature, 2014, 516, 181. 